\title{
Key Construction Monitoring Technology for Long-Span Continuous Girder Bridge
}

\author{
Fei Zhang*, Yan Wang \\ School of Engineering, Fujian Jiangxia University, Fuzhou,Fujian, China \\ *Corresponding author.
}

\begin{abstract}
This paper integrates a monitoring practice for the construction of a long-span continuous girder bridge to explore strain measurement and geometric shape control technology. In doing so, the actual stress of the bridge in the cantilever-construction stage is identified, and the influence of ambient temperature on the geometric shape control of the main girder is eliminated. According to linear creep theory, a strain correction method based on the superposition principle is proposed to remove the strain induced by concrete shrinkage and creep. By identifying the pattern of the solar thermal effect on the main girder geometry, a double in-situ measurement interpolation method is proposed to predict the adjusted value of formwork erection elevation. The results show that the deviation between the measured and corrected stress values on the root section of the main girder under the maximum cantilever state of the main girder is $16 \%-23 \%$, which verifies the necessity of strain correction. The corrected values of measured stress on each controlled section are essentially identical to the calculated values, and both have consistent change patterns throughout the construction process, which verifies the validity of the strain correction method. During the cantilever-construction stage, the vertical deformation of the main girder owing to the solar thermal effect is parabolic and significant; hence, the main girder geometry should be measured prior to sunrise. The double in-situ measurement interpolation method can effectively eliminate the adverse effects of solar thermal when lofting the vertical formwork elevation in a non-ideal period.
\end{abstract}

Keywords: Continuous girder bridge, construction monitoring, strain correction, concrete shrinkage and creep, solar thermal effect, formwork erection elevation

\section{Introduction}

The construction of long-span continuous girder bridges and continuous rigid-frame bridges is generally based on cantilever casting, during which effective stress monitoring and geometric shape monitoring are required[1-2]. Stress monitoring evaluates the safety of structural forces by testing the stress state of the structure during construction. Stress testing generally adopts steel-wire strain gauges, by which concrete strain can be tested and converted to stress according to the elasticity relationship[3]. The measured strain includes a number of elements, such as elastic strain under load, strain caused by concrete shrinkage, strain caused by concrete creep, and strain caused by temperature effect. However, only the elastic strain under load is required, as it contains stress information; the other three strains are non-stress strains. Accordingly, to obtain the actual strain of the structure, the non-stress strains must be removed from the total recorded strain value, but this is not an easy task.

Geometric shape monitoring can determine the formwork erection elevation of the girder block by setting the precamber to ensure that the final linear shape of the bridge conforms to the design objective[4-5]. Vertical deformation can occur to the main girder during bridge construction due to the ambient temperature. Test results vary when examining the linear shape of a bridge at different times. The ambient temperature adversely affects the lofting of the formwork elevation[6]. At present, the engineering practice avoids the solar thermal effect by collecting elevation data before dawn, when the thermal field distribution in the girder body is relatively uniform and the impact of the ambient temperature on the main girder linear shape is small. However, it is not realistic to carry out tests before first sunlight, given that construction is ongoing and the project cannot be halted just because other time periods are not ideal for testing. Therefore, it is vital to find effective ways to eliminate the adverse effects of solar thermal when the lofting of the formwork elevation is carried out at non-ideal period.

Many studies have examined stress measurement technologies with respect to eliminating the solar thermal effect.

ISSN: 0010-8189

(c) CONVERTER 2021

www.converter-magazine.info 
Yang Liu[7] installed strain gauges in the neutral axis position of the main girder, separated the creep value based on concrete creep coefficient, and established the relationship between concrete stress and strain increment considering the creep effect. Qianhua $\mathrm{Yu}[8]$ theoretically derived a general finite element algorithm based on the initial strain of a spatial girder unit, calculated the non-stress strain of concrete, and proved that the precision of the proposed method meets engineering needs through numerical example verification. Based on an in-situ test and the installation of a stress-free sensor, Zhongfu Xiang[9] found a correlation between strain increment and concrete stress and proposed a modified stress increment method. Xuming Song[10] studied the effect of temperature gradient on the bridge linear shape during cantilever construction, the results of which suggest that the temperature gradient should be factored into the identification of the formwork elevation of the girder block given that the deflection at the cantilever end of the main girder can be as large as $46.0 \mathrm{~mm}$ under the solar thermal effect. According to Fuchun Song[11], the orderly erecting analysis method is appropriate for the calculation of structural stress during construction, the inversion analysis method is appropriate for determining the formwork erection elevation, and the stress-free state analysis method is appropriate for the prediction of structural stress and the linear condition. Yaqiong Sun[12] used the time-varying mean value to obtain the time-history curve of the solar thermal effect and proposed a method to remove the temperature effect from the strain measurement. Yongbao Wang[13] derived a formula based on the age-adjusted effective modulus method for calculating the self-stress of a reinforced concrete girder along the height direction under non-uniform shrinkage and creep effect.

Based on the construction monitoring practice of the Shuidong Bridge in Fujian Province, in this paper, we separate the strain values reflecting the actual force from the measured data of the strain gauge and propose a strain correction method to eliminate the strain induced by concrete shrinkage and creep, as well as a calculation method for stress and strain owing to temperature difference caused by the solar thermal effect. Regarding geometric shape control technology, the pattern of the solar thermal effect on the linear shape of the main girder is identified, and a method is proposed to eliminate the adverse effects of solar thermal on the lofting of the formwork erection elevation. In the end, these key technologies are applied to practical engineering with positive results obtained. The research results can act as a reference for the construction monitoring of bridges of the same type.

\section{Engineering Overview}

The Shuidong Bridge is located at 304 Provincial Road in Fujian Province. The urban-facing side of the main bridge is a prestressed concrete variable cross-section continuous box-girder bridge; the bridge span lengths are 36 $+56+36 \mathrm{~m}$, and the design loading is Class II Highway. The upper structure has left and right parts, and the single bridge uses a single-box single-cell variable cross-section continuous box girder, the height of which at the fulcrum is $3.4 \mathrm{~m}$ and the mid-span is $1.9 \mathrm{~m}$. The curve of the girder bottom changes according to a quadratic curve. The top slab of the box girder has a width of $12 \mathrm{~m}$, the bottom slab has a width of 5.1-6.1 m, and the slope rate of the web slab is $3: 1$. The lower structure is a thin-walled vase-shaped pier with a single pier body and a single foundation. The foundation consists of four bored piles (in two rows), each with a diameter of $1.5 \mathrm{~m}$.

The bridge uses the hanging basket system for cantilever casting; the main girders within the 5-m range on both sides of the central point are denoted as No. 0 block, and the cantilever casting is divided into six blocks with each block being 3-4 m long. No. 0 block on the supporting frame is the first to be cast, after which the remaining blocks are constructed symmetrically on the two sides. Finally, the mid-span and side-span are closed, and the length of the closure block is $2 \mathrm{~m}$.

Stress monitoring is carried out during construction to ensure the stress safety of the bridge. The selected section under stress monitoring is shown in Fig. 1, including the root section of the main girder (B-B and C-C), the critical section of the side span $(A-A)$, and the middle section of the main span (D-D). Each section tested was designed with three measuring points on the top and bottom slabs, and each measuring point has a buried GHB-3 steel-wire strain gauge and a BGK-3700 thermometer. The arrangement of the stress measuring points is shown in Fig. 2. To prevent damage to the elements in the case of concrete stirring, the testing element on the top plate was placed below the upper rebar, and the test element for the bottom was placed above the lower rebar. Stress monitoring was carried out for the concrete casting, prestressed tension, side-span closure, and mid-span closure.

ISSN: 0010-8189

www.converter-magazine.info 


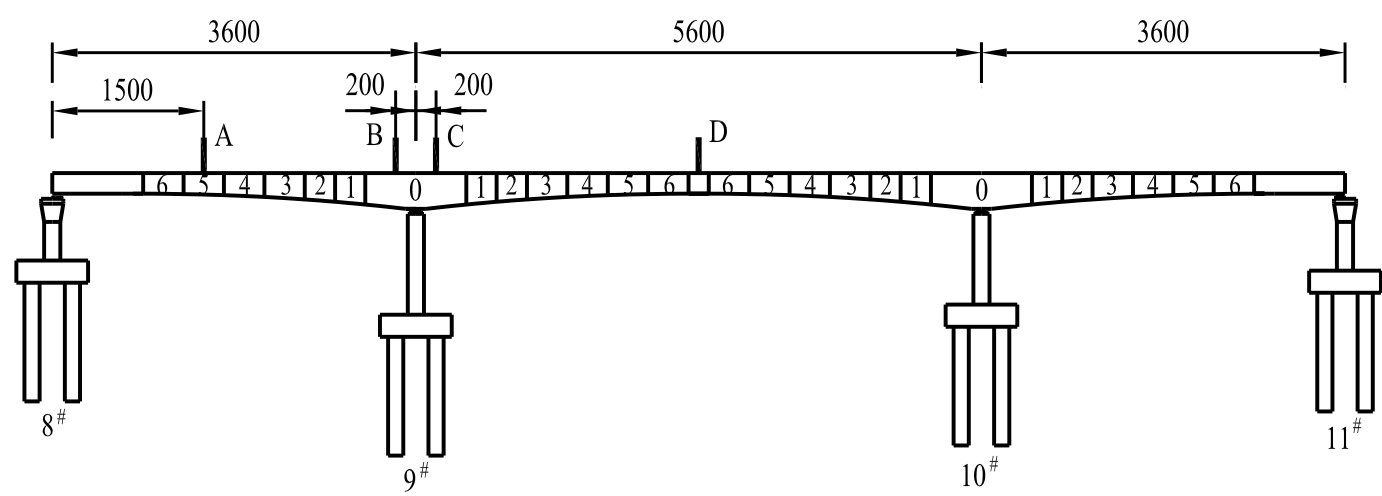

“ | ": cross section of stress monitoring; “0-6":cantilever casting block number.

Fig 1: Arrangement of cross section of stress monitoring/cm.

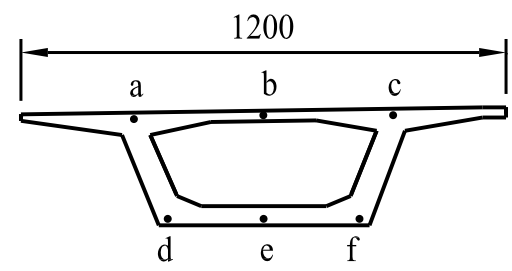

Fig 2: Arrangement of stress measuring points/cm.

Orderly erecting simulation was carried out for the construction process using MIDAS/Civil bridge-analysis software. The whole bridge was separated into 118 girder elements, and the finite element model is shown in Fig. 3. The construction simulation for a standard girder-block was divided into three operations, i.e., the forward movement of the hanging basket equipment, concrete casting, and the prestressed tension. The calculation factors included the wet weight after the girder-block casting, the self-weight when the girder block is loaded, prestressed and the load on the hanging basket equipment.

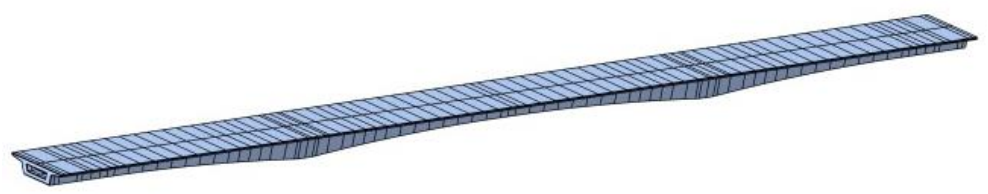

Fig 3: Finite element model.

\section{Strain Measurement and Correction Method}

\subsection{Total test strain}

The strain gauge used in the bridge stress monitoring relies on consistent axial deformation with the measuring points to detect the girder strain. However, the elongation or shrinkage of the girder body reflects not only the elastic strain produced by the external force but also the deformation caused by concrete shrinkage and creep and temperature effect[14]. The main girder during the cantilever-construction stage is a static structure, theoretically, concrete shrinkage and creep and the solar thermal effect do not produce internal forces, which are presented as virtual strain and referred to as non-stress strain. In stress monitoring, it is difficult to separate the strain values reflecting the real force from the measured data of the strain gauge, because concrete shrinkage and creep are time sensitive, and the solar thermal effect is random.

ISSN: 0010-8189

www.converter-magazine.info 
The total strain tested by the strain gauge is expressed as follows:

$$
\varepsilon(t)=\varepsilon_{i}\left(\tau_{0}\right)+\varepsilon_{c}\left(t, \tau_{0}\right)+\varepsilon_{s}\left(t, \tau_{s}\right)+\varepsilon_{T}(t)
$$

where $\varepsilon_{i}\left(\tau_{0}\right)$ denotes the elastic strain when loaded at the time $\tau_{0}, \varepsilon_{c}\left(t, \tau_{0}\right)$ is the concrete creep, $\varepsilon_{s}\left(t, \tau_{s}\right)$ is the strain caused by concrete shrinkage, and $\varepsilon_{T}(t)$ is the strain caused by the temperature effect.

\subsection{Strain correction method to remove concrete shrinkage and creep}

Volume shrinkage occurs during concrete solidification and hardening and as water disperses. The increasing concrete strain under the constant stress is called creep. Concrete shrinkage and creep increase with time: a fast rate in the early stage, a gradually slower rater thereafter, and stability is reached after a long time. According to the experimental results of [15-17], most shrinkage deformation occurs from 6 to 12 months, whereas most creep appears from 1 to 2 years with the first 3 to 6 months having the most rapid deformation. The cantilever-casting stage is the period when concrete shrinkage and creep develops rapidly, and its non-stress strain has a negative impact on the actualstress test of the structure.

Concrete creep is related to a number of factors, such as stress, loading age, loading duration, mixture ratio of materials, humidity, and component size. During cantilever construction, the main girder is cast block by block, tensile prestress is applied segment by segment, and loading is applied to the structure in batches. For different loading batches, the corresponding loading age is different. According to China's Specifications for Design of Highway Reinforced Concrete and Prestressed Concrete Bridges and Culverts, When the ratio of the compressive stress to the strength of concrete is in the range of $0.4-0.6$, the concrete creep and the stress have a linear relationship. Generally, the compressive stress of concrete components does not exceed 0.5 times the strength, which meets the condition for linear creep; therefore, the superposition principle can be used: the total concrete creep value is equal to the sum of the creep value caused by the stress increment in each batch.

At different times $\tau_{i}(i=0,1,2, \cdots n)$, stress increments are imposed on the concrete structure batch by batch, and the total strain value at any moment can be expressed as follows:

$$
\varepsilon(t)=\sum_{i=0}^{n} \frac{\Delta \sigma\left(\tau_{i}\right)}{E\left(\tau_{i}\right)} \square\left[1+\varphi\left(t, \tau_{i}\right)\right]+\varepsilon_{s}\left(t, \tau_{s}\right)
$$

where $\Delta \sigma\left(\tau_{i}\right)$ denotes the value of the increased stress imposed at $\tau_{i}, E\left(\tau_{i}\right)$ is the elastic modulus of concrete at loading age $\tau_{i}, \varepsilon_{s}\left(t, \tau_{s}\right)$ is the strain induced by concrete shrinkage, $\tau_{s}$ is the loading age when shrinkage starts, and $\varphi\left(t, \tau_{i}\right)$ is the creep coefficient, which can be obtained through testing the on-site sample blocks or calculated according relevant design specifications.

When carrying out on-site stress monitoring, assuming that the strain gauge measured data is measured immediately after each stress increment is applied, i.e., at the test time $t_{i}=\tau_{i}$, the total strain tested at $\tau_{i}$ can be expressed as follows:

$$
\varepsilon\left(\tau_{i}\right)=\frac{\Delta \sigma\left(\tau_{\mathrm{i}}\right)}{E\left(\tau_{i}\right)} \square\left[1+\varphi\left(\tau_{i}, \tau_{i}\right)\right]+\sum_{j=0}^{i-1} \frac{\Delta \sigma\left(\tau_{j}\right)}{E\left(\tau_{j}\right)} \square\left[1+\varphi\left(\tau_{i}, \tau_{j}\right)\right]+\varepsilon_{s}\left(\tau_{i}, \tau_{s}\right) \text { (3) }
$$

ISSN: 0010-8189

C CONVERTER 2021

www.converter-magazine.info 
where $\varepsilon\left(\tau_{i}\right)$ is the measured value of the strain gauge at the time $\tau_{i}$, which is subtracted the initial value of the strain gauge.

In Eq. (3), given that $\varphi\left(\tau_{i}, \tau_{i}\right)=0$, we can derive the stress increment imposed atthe time $\tau_{i}$ :

$$
\Delta \sigma\left(\tau_{i}\right)=\left\{\varepsilon\left(\tau_{i}\right)-\varepsilon_{s}\left(\tau_{i}, \tau_{s}\right)-\sum_{j=0}^{i-1} \frac{\Delta \sigma\left(\tau_{j}\right)}{E\left(\tau_{j}\right)} \square\left[1+\varphi\left(\tau_{i}, \tau_{j}\right)\right]\right\} \square E\left(\tau_{i}\right)
$$

When $t_{0}=\tau_{0}$, the stress increment is the initial stress applied, as expressed by Eq. (5):

$$
\Delta \sigma\left(\tau_{0}\right)=\left[\varepsilon\left(\tau_{0}\right)-\varepsilon_{s}\left(\tau_{0}, \tau_{s}\right)\right] \square E\left(\tau_{0}\right)
$$

Therefore, at $\tau_{i}$, the real strain (i.e., corrected strain value) after excluding concrete shrinkage and creep is represented by Eq. (6):

$$
\varepsilon_{i}\left(\tau_{i}\right)=\sum_{i=0}^{n} \frac{\Delta \sigma\left(\tau_{i}\right)}{E\left(\tau_{i}\right)}
$$

\subsection{Treatment method of solar thermal effect}

The ambient temperature affects the deformation and force of the bridge structure through the material linear expansion coefficient. The temperature effect mainly includes both seasonal and solar temperature difference. Normal seasonal temperature differences result in heating and cooling of the structure. In this case, the temperature field over the cross section is evenly distributed. Moreover, the main girder is a static structure in the cantileverconstruction stage, which can expand without causing stress while demonstrating free-temperature strain. The solar thermal effect refers to the uneven temperature change of the structure cross section due to solar thermal radiation. In this case, the temperature gradient forms along the girder height direction[18-21]. Moreover, the mutual restraint between the fiber layers in the girder body brings about stress and strain due to cross-section temperature difference.

Under the solar thermal effect, assuming that the temperature distribution along the height direction of the girder section is $T(y)$, the free strain on the section is $\alpha T(y)$, where $\alpha$ is the linear expansion coefficient. Under the mutual restraint between the internal fiber layers, the actual deformation conforms to the condition of the flatsection assumption, and the constrained strain of concrete can be expressed as $\varepsilon_{0}+k y$, where $\varepsilon_{0}$ is the strain value of the girder bottom, $k$ is the curvature of a unit-length girder after bending deformation, and $y$ is the height of the calculated point on the cross section from the girder bottom. Fig. 4 shows the cross-section strain under the solar thermal effect.

ISSN: 0010-8189

www.converter-magazine.info 


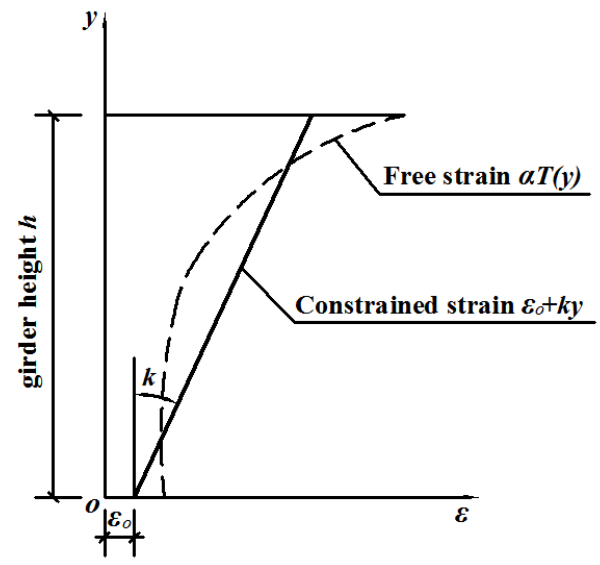

Fig 4: Cross-section strain under the solar thermal effect

The strain due to cross-section temperature difference at height $y$ can be calculated according to Eq. (7):

$$
\varepsilon(y)=\alpha T(y)-\left(\varepsilon_{0}+k y\right)
$$

The concrete constitutive relationship can then be introduced and the balance equation established as follows:

$$
\left\{\begin{array} { l } 
{ \sum F _ { X } = 0 } \\
{ \sum M = 0 }
\end{array} \Rightarrow \left\{\begin{array}{l}
\int_{0}^{h} E_{c} \varepsilon(y) b(y) \mathrm{d} y=0 \\
\int_{0}^{h} E_{c} \varepsilon(y) b(y) y \mathrm{~d} y=0
\end{array}\right.\right.
$$

where $E_{c}$ is the concrete elasticity modulus, and $b(y)$ is the girder width at height $y$.

By solving Eq. (8), the value of $\varepsilon_{0}$ and $k$ can be obtained, and the temperature-difference stress and corresponding strain can be calculated by Eq. (7).

When applying the abovementioned theory to identify the temperature-difference stress and strain caused by the solar thermal effect, related calculations should be performed after measuring the temperaturefield distribution on the girder cross section. If this condition is not allowed in practical engineering, strain measurements are recommended to be conducted prior to sunrise, when the temperature field inside the structure is evenly distributed, by which we can avoid the solar thermal effect. Nevertheless, the measured strain value must still exclude the free-temperature strain.

\subsection{Setting the initial strain value}

After installation, the strain gauge is initially affected by a number of factors, such as temporary construction load, early concrete shrinkage, and concrete hydration heat. Temporary construction load refers to the fact that concrete casting or stirring might act on the strain gauge and cause changes in the measured data. The concrete hydration heat reduces the frequency of the vibrating wire strain gauge, which increases the compressive strain in the strain gauge. Long-span bridges generally use thin-walled box girders, which have a fast rate of hydration heat dissipation. Generally, three to five days after concrete is cast, the hydration heat is essentially dissipated, and the measurement function of the strain gauge is restored. Therefore, the initial value of the strain gauge is recommended to be set when the concrete age is five days.

3.5 Concrete elasticity modulus

ISSN: 0010-8189

(C) CONVERTER 2021

www.converter-magazine.info 
Converting the measured strain of concrete into stress requires the elastic modulus. Concrete strength and the elasticity modulus both increase with age, and, eventually, they tend to converge. The standard values of the axial compressive strength and elastic modulus of C55 concrete stipulated in China's current design specifications are 35.5 and 35,500 MPa, respectively. However, the actual concrete elasticity modulus is usually different from the specified value, so it needs to be measured during field tests. Table 1 shows the measured values of the elastic modulus of $\mathrm{C} 55$ concrete in this project at various ages, from which it is evident that the measured elastic modulus at 28 days is 1.116 times the specified value.

Table 1 Elastic modulus of a $\mathrm{C} 55$ concrete standard prism.

\begin{tabular}{ccc}
\hline $\begin{array}{c}\text { Age/ } \\
\text { Days }\end{array}$ & $\begin{array}{c}\text { Axial compressive } \\
\text { strength/MPa }\end{array}$ & $\begin{array}{c}\text { Elastic } \\
\text { modulus/MPa }\end{array}$ \\
\hline 3 & 26.21 & 31,602 \\
7 & 37.60 & 35,491 \\
14 & 39.98 & 37,853 \\
28 & 41.19 & 39,618 \\
\hline
\end{tabular}

\section{Solar Thermal Effect on Linear Shape of Main Girder and Countermeasures}

\subsection{Solar thermal effect on linear shape of main girder}

\subsubsection{On-site measurements}

During cantilever construction, the temperature gradient caused by the solar thermal effect results in large vertical deformation to the main girder. Measurements of the elevation of the top surface of the main girder of 9\# pier were conducted at 6 am and $3 \mathrm{pm}$ under the maximum cantilever state. It is believed that the temperature field in the girder at 6 am is evenly distributed, and barely any vertical deformation to the main girder is observed; at $3 \mathrm{pm}$, when the top slab is under solar heat radiation, the temperature in the girder decreases along the height direction, and the main girder has large vertical deformation. The difference between the measured elevation values at the two times is the vertical deformation of the main girder in the case of solar thermal effect. Fig. 5 shows the vertical deformation of the main girder due to solar thermal effect. The vertical deformation is positive upwards.

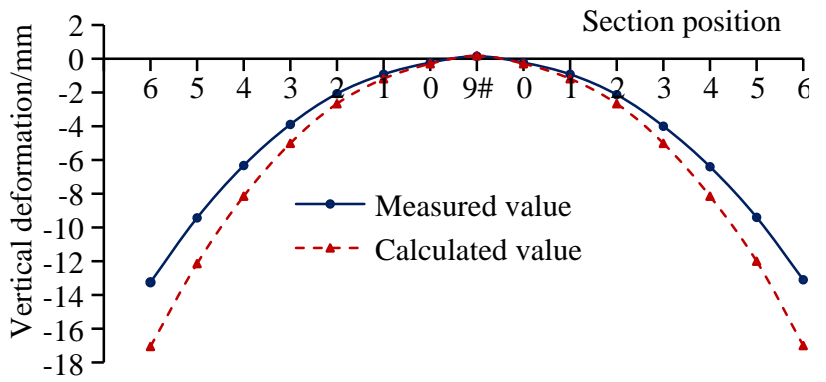

In the abscissa axis, "1-6 ": end position of the No. i block; " 9\#": fulcrum center of the 9\# pier. Fi. 5: Vertical deformation of the main girder caused by solar thermal effect.

From Fig 5, evidently, during cantilever construction, the vertical deformation of the main girder due to solar thermal effect has a parabolic shape. The center of the fulcrum at the top of the pier is the vertex of the parabola, which essentially does not deform. The cantilever segment of the main girder produces downward vertical deformation. The maximum measured deformation is $-13.31 \mathrm{~mm}$, which occurs at the end of the cantilever segment.

4.1.2 Finite element analysis

According to China's General Specifications for Design of Highway Bridges and Culverts, the solar thermal effect should be calculated using a vertical temperature-gradient curve. The selection of the basic temperature values is

ISSN: 0010-8189

(C) CONVERTER 2021

www.converter-magazine.info 
related to the material and thickness of the bridge-deck paving layer. Asphalt pavement is yet to be constructed during the cantilever-construction stage, so the roof of the concrete girder is directly exposed to sunlight radiation. Therefore, the setting of basic temperature values is based on concrete pavement, as in the specifications. The top of the structure has a temperature of $25^{\circ} \mathrm{C} ; 100 \mathrm{~mm}$ from the top, the temperature is $6.7^{\circ} \mathrm{C} ; 400 \mathrm{~mm}$ from the top, the temperature is $0^{\circ} \mathrm{C}$; and at the structure bottom, the temperature is $0^{\circ} \mathrm{C}$. Moreover, the control points transition in a straight line. The finite element software MIDAS/Civil was used to establish the calculation model of the main girder of the 9\# pier under the maximum cantilever state, the abovementioned temperature-gradient curve was adopted for analysis, and the vertical deformation of the main girder was obtained.

From Fig. 5, evidently, owing to the solar thermal effect, the regularity of the vertical deformation of the main girder calculated by finite element analysis is consistent with the measured results, and both have a parabolic shape. The maximum calculated deformation is $-17.22 \mathrm{~mm}$, which occurs at the end of the cantilever segment. The deviation between the calculated and measured values can be attributed to the selection of the design control load under the solar thermal effect for finite element analysis, i.e., the maximum state. This state mostly occurs when solar heat radiation intensity is at a peak.

\subsection{Countermeasures to eliminate solar thermal effect}

From the above analysis, solar thermal effect has a significant impact on the vertical deformation of the main girder. Therefore, measurements should be conducted when solar heat radiation is at a minimum, which is usually before sunrise. However, on-site construction must follow the outlined schedule and conduct lofting of the formwork elevation; therefore, waiting for an ideal measurement time is impractical. Accordingly, the formwork elevation of the main girder must consider the instantaneous deformation of the main girder caused by solar thermal effect and remove the effect to achieve precise control of the linear shape.

Owing to solar thermal effect, the vertical deformation of the main girder takes a parabolic shape during the cantilever-construction phase. On this basis, a double in-situ measurement interpolation method based on Lagrangian interpolation theory is proposed to negate the solar thermal effect on the formwork erection elevation. The principle is as follows: under the solar thermal effect, curve fitting is performed for the measured vertical deformation values of the three cast girder blocks adjacent to the front of the block to be erected, after which interpolation calculations are used to predict the adjusted erection elevation value considering solar thermal effect for the block to be erected.

Under the effect of solar thermal effect, the vertical deformation curve based on the Lagrangian quadratic equation of the main girder can be expressed by Eq. (9):

$$
y=\frac{\left(x-x_{2}\right)\left(x-x_{3}\right)}{\left(x_{1}-x_{2}\right)\left(x_{1}-x_{3}\right)} y_{1}+\frac{\left(x-x_{1}\right)\left(x-x_{3}\right)}{\left(x_{2}-x_{1}\right)\left(x_{2}-x_{3}\right)} y_{2}+\frac{\left(x-x_{1}\right)\left(x-x_{2}\right)}{\left(x_{3}-x_{1}\right)\left(x_{3}-x_{2}\right)} y_{3}=\sum_{i=1}^{3}\left[\prod_{\substack{j=1 \\ j \neq i}}^{3}\left(\frac{x-x_{j}}{x_{i}-x_{j}}\right)\right] y_{i}
$$

where ${ }^{x_{1}}, x_{2}$, and ${ }^{x_{3}}$ are the longitudinal positions of the ends of the three cast blocks adjacent to the front of the block to be erected; $y_{1}, y_{2}$ and $y_{3}$ are the measured values of vertical deformation at the corresponding positions $x_{1}, x_{2}$, and $x_{3}$.

Substituting the longitudinal direction position ${ }^{x_{k}}$ at the end of the block to be erected into Eq. (9), the adjusted erection elevation value for the block to be erected considering solar thermal effect can be predicted:

$$
y_{k}=\sum_{i=1}^{3}\left[\prod_{\substack{j=1 \\ j \neq i}}^{3}\left(\frac{x_{k}-x_{j}}{x_{i}-x_{j}}\right)\right] y_{i}=\sum_{i=1}^{3}\left(\prod_{\substack{j=1 \\ j \neq i}}^{3} \frac{D_{k j}}{D_{i j}}\right) y_{i}
$$

ISSN: 0010-8189

(c) CONVERTER 2021

www.converter-magazine.info 
where $D_{i j}$ is the distance between block i and block j, (when i $>\mathrm{j}, \quad D_{i j}$ takes a positive value, and, when $\mathrm{i}<\mathrm{j}$, it takes a negative value); ${ }^{D_{j j}}$ is the distance between the to-be-erected block and block $\mathrm{j}$, which takes a positive value.

The double in-situ measurement interpolation method consists of two steps. These are outlined below.

(1) Measure the elevation of the three cast blocks in front of the adjacent blocks to be erected before sunrise and when the template is positioned. It is believed that, before sunrise, the temperature field in the girder body is uniformly distributed, and the main girder essentially has no vertical deformation; when the formwork is positioned, the main girder is subjected to solar heat radiation, which causes vertical deformation. The difference between the two measured elevations is the vertical deformation of the three cast blocks under the effect of solar thermal effect.

(2) Use Eq. (10) to calculate the adjusted erection elevation value of the block to be erected under the solar thermal effect.

\section{Results and Discussion}

5.1 Engineering application of the strain correction method

The strain correction method was applied to the strain measurements of the main bridge of the Shuidong Bridge. Combining the measured elastic modulus on site, the actual stress of the bridge during construction was calculated. The construction of the main girder at the 9\# pier under the maximum cantilever state is taken as an example. Table 2 shows the stress of the root section (B-B) of the main girder when the prestressed tension, and the tensile stress is positive.

From Table 2, it is evident that the box girder has a considerable shear lag effect is evident. On the top and bottom plates of the box girder, the stress in the middle is less than the stress at the web plate. The deviation between the measured and corrected stress values on the root section of the main girder is in the range of $16 \%-23 \%$, indicating that the strain induced by concrete shrinkage and creep and solar thermal effect accounts for a large proportion of the total strain, which verifies the necessity of strain correction. The corrected value of stress is basicallyconsistent with the calculated value, which verifies the effectiveness of the proposed method.

Table 2 Stress of the root section $(B-B)$ of the main girder under the maximum cantilever state.

\begin{tabular}{ccccc}
\hline $\begin{array}{c}\text { Measuring } \\
\text { point number }\end{array}$ & $\begin{array}{c}\text { Measured } \\
\text { value/MPa }\end{array}$ & $\begin{array}{c}\text { Corrected } \\
\text { value/MPa }\end{array}$ & Deviation & $\begin{array}{c}\text { Calculated } \\
\text { value/MPa }\end{array}$ \\
\hline a & -9.47 & -7.89 & $20 \%$ & -7.91 \\
b & -8.18 & -7.05 & $16 \%$ & -7.91 \\
c & -10.0 & -8.15 & $23 \%$ & -7.91 \\
d & -8.18 & -6.87 & $19 \%$ & -6.86 \\
e & -7.22 & -6.17 & $17 \%$ & -6.86 \\
f & -8.41 & -7.01 & $20 \%$ & -6.86 \\
\hline
\end{tabular}

5.2 Engineering application of the double in-situ measurement interpolation method

The double in-situ measurement interpolation method was applied to the lofting of the formwork erection elevation of the main bridge of the Shuidong Bridge. Taking the No. 6 block of the main girder at pier 10\# as an example, the positioning time of the erection elevation was $5 \mathrm{pm}$. The elevation measurements of the No. 5, No. 4, and No. 3 blocks adjacent to the No. 6 block were carried out at 6 am and $5 \mathrm{pm}$. The two measurement results are shown in Table 3.

ISSN: 0010-8189

(C) CONVERTER 2021

www.converter-magazine.info 
Table 3 Two elevation measurement results.

\begin{tabular}{cccc}
\hline Block number & $\begin{array}{c}\text { Elevation } \\
\text { measurement at } 6 \\
\text { am/m }\end{array}$ & $\begin{array}{c}\text { Elevation measurement } \\
\text { when positioning the } \\
\text { formwork/m }\end{array}$ & $\begin{array}{c}\text { Vertical deformation } \\
\text { caused by solar thermal } \\
\text { effect/mm }\end{array}$ \\
\hline 3 & 119.8028 & 119.7997 & -3.1 \\
4 & 119.8234 & 119.8184 & -5.0 \\
5 & 119.8416 & 119.8342 & -7.4 \\
\hline
\end{tabular}

Using Eq. (10), the adjusted erection elevation value for the No. 6 block considering solar thermal effect is -10.3 $\mathrm{mm}$. On the basis of theoretical elevation of the formwork, the monitoring personnel reduced the elevation by 10.3 $\mathrm{mm}$. In the evening of the same day, the block was cast.

In the morning of the second day, the elevation of No. 6 block of the main girder was remeasured. The measured value is consistent with the theoretical target value, which verifies the validity of the double in-situ measurement interpolation method.

\subsection{Stress monitoring results}

Owing to space limitations, only the stress monitoring results of the root section $(\mathrm{C}-\mathrm{C})$ of the main girder during construction are compared with the calculated values of the finite element analysis, the results of which are shown in Fig. 6. The tensile stress is positive. Through the comparative analysis of measured and calculated stresses, a number of conclusions can be drawn. First, during the construction process, tensile stress did not occur to the root section of the main girder, the compressive stress value was less than the stress limit of components as required in the specifications, and the structural force was within the safety scope. Second, the corrected measured value of stress is essentially consistent with the calculated value, and both change in consistent ways with the construction process, which verifies the effectiveness of the strain correction method with respect to eliminating concrete shrinkage and creep. Third, during cantilever construction of the root section of the main girder, the stress on the top and bottom plates of the main girder has a typical wave shape. In the mid-span closure stage, the stress changes greatly.

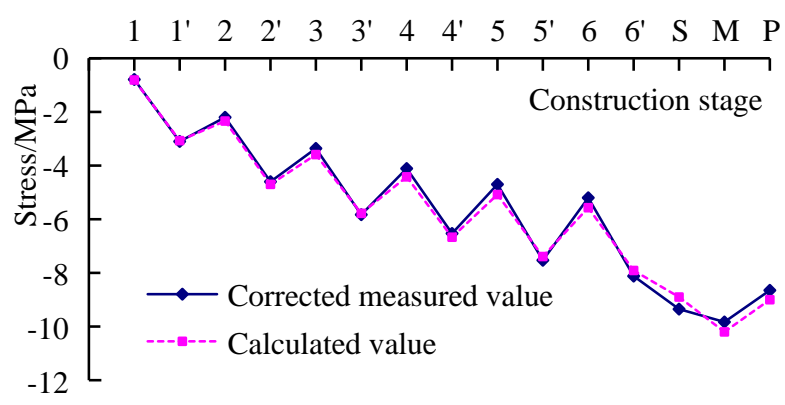

(a) Measuring point $c$ of the cross section

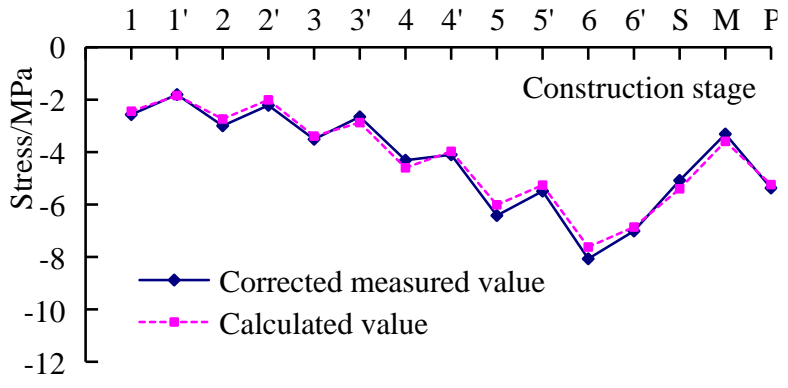

(b) Measuring point $f$ of the cross section

In the abscissa axis, "1-6": casting concrete of the No. i block; "1'-6" ": prestressed tension of the No. $i$ block; "S": side-span closure; " $M$ ": mid-span closure; and " $P$ ": construction of the bridge-deck pavement

Fig 6: Stress of the root section $(C-C)$ of the main girder.

\section{Conclusions}

This paper integrated a monitoring practice for the construction of a long-span continuous girder bridge to explore strain measurement technology and geometric shape control technology. The conclusions outlined below were drawn.

In the stress monitoring process, the total strain recorded by the strain measurement instrument includes the elastic strain under load, the strain induced by concrete shrinkage and creep, and the strain caused by the solar thermal

ISSN: 0010-8189

C CONVERTER 2021

www.converter-magazine.info 
effect. According to linear creep theory, a strain correction method based on the superposition principle was proposed to eliminate the strain caused by concrete shrinkage and creep, and the calculation method for stress and strain owing to temperature difference caused by solar thermal effect was explained to separate the non-stress strain values and obtain the actual stress of the structure.

In engineering application, the deviation between the measured and corrected stress values on the root section of the main girder was $16 \%-23 \%$, indicating that the strain induced by concrete shrinkage and creep and solar thermal effect accounts for a large proportion of the total strain, which verified the necessity of strain correction. The corrected value of the stress on each controlled section of the structure was essentially identical to the calculated value, and both had consistent change patterns throughout the construction process, which verified the effectiveness of the proposed strain correction method.

In the cantilever-construction stage, the vertical deformation of the main girder caused by solar thermal effect had a parabolic shape, and the deformationwas significant. The construction measurement shouldbe conducted before sunrise if possible. When lofting the formwork elevation in a non-ideal period, a double in-situ measurement interpolation method based on Lagrangian interpolation theory was proposed to predict the adjusted value of the formwork erection elevation considering the solar thermal effect. An engineering application example proved that this method can effectively eliminate the adverse effects of solar thermal.

No tensile stress was observed during the construction of the bridge, the compressive stress was within the stress limit in the construction phase as required in the specifications, and the structural force was within the safety scope.

\section{Acknowledgments}

The authors acknowledge the National Natural Science Foundation of China (Grant: 51578161), Research Project for Young and Middle-aged Teachers of Fujian Provincial Department of Education [Grant: JAT200374].

\section{References}

[1] Y.F. Gao, Y.Q. Yang, Q.H. Pu, X.B. Li,"State-of-the-art Review of the Theory of Bridge Construction Monitoring and Control and Its Application in 2019,"Journal of Civil and Environmental Engineering, vol. 42, no. 5, pp. 98-105, 2020.

[2] M.Z. Xie, Y.Q. Yang, X.B. Li, Z.C. Wu,"Deformation Analysis of Cantilever Construction of Different Long-span Continuous Girder Bridges for High-speed Railway,"Journal of Shenyang Jianzhu University: Natural Science, vol. 35, no. 1, pp. 20-29, 2019.

[3] A.P. Guo, A.J. Jiang, W.S. Zhang, “Construction Control of Zhongjian River Bridge on Enshi-Laifeng Expressway,’Bridge Construction, vol. 48, no.6, pp. 110-115, 2018.

[4] X.G. Wu, P.H. An, X.Q. Huang, P. Zheng, Y.L. Li,"'Influence Factor Analysis and Curve Fitting of Camber of Continuous Beam Bridge in Cantilever Construction,’Journal of Chongqing Jiaotong University: Natural Science, vol. 37, no. 3, pp. 1-4, 2018.

[5] H.D. Chen, X.G. Wu, S.S. Yao, J.Q. Liu, "Estimation Formula of Pre-camber in Completed Bridge Stage at Mid-span of Continuous Rigid Frame Bridge,"Engineering Journal of Wuhan University, vol. 50, no. 1, pp. 114-119, 2017.

[6] Y.J. Liu, J. Liu, N. Zhang,"Review on Solar Thermal Actions of Bridge Structures,"China Civil Engineering Journal, vol. 52, no. 5, pp. 59-78, 2019.

[7] Y. Liu, R.H. Tu, “Testing and Analysis of Concrete Stress in Construction of Main Girder of Yibin Changjiang River Bridge,’Bridge Construction, no. 2, pp. 71-73, 2008.

[8] Q.H. Yu, “Stress Analysis and Measurement of Long-span Concrete Bridge in Process of Construction Supervisory Control,"China Journal of Highway and Transport, no. 2, pp. 68-73, 2008.

[9] Z.F. Xiang, X. Ran, L. Lai,"Stress Modification of Bridge Construction Based on the In-situ Experiment of Bridge,’Journal of Chongqing Jiaotong University: Natural Science, vol. 35, no. 3, pp. 6-10, 2008.

[10] X.M. Song, H. Melhem, J. Li, Q.Y. Xu, L.J. Cheng, "Effects of Solar Temperature Gradient on LongSpan Concrete Box Girder during Cantilever Construction,’Journal of Bridge Engineering, vol. 21, no. 3, pp. 04015061, 2016. 
[11] F.C. Song, X. Zhang, C. Chen, X.L. Li,"Structural Control Analysis during Construction of Cantilever of Long-span Pre-stressed Concrete Continuous Girder Bridge,"Journal of Shenyang Jianzhu University: Natural Science,vol. 33, no. 2, pp. 226-234, 2017.

[12] Y.Q. Sun, Z.Z. Zhao,"Real-time Seperation of Temperature Effect on Dynamic Strain Monitoring and Moving Load Identification of Bridge Structure,” Engineering Mechanics, vol. 36, no. 2, pp. 186-194, 2019.

[13] Y.B. Wang, P. Liao, Y. Jia, R.D. Zhao, D.B. Wu, "Study on Self-stress Caused by the Non-uniform Concrete Creep and Shrinkage in Reinforced Concrete Beams,"Journal of the China railway Society, vol. 41, no. 2, pp. 137-145, 2019.

[14] Ri. Malm, H. Sundquist, “Time-dependent Analyses of Segmentally Constructed Balanced Cantilever Bridges,"Engineering Structures, vol. 32, no. 4, pp. 1038-1045, 2009.

[15] J.H. Mao, F. Lu, Y. Zhang, J.H. Zeng, J.B. Yan,"Modification of Creep Model Based on Experiment and Bridge Linear Analysis Method,"Journal of Chongqing Jiaotong University: Natural Science, vol. 38, no. 12, pp. 38-44, 2019.

[16] W.W. Han, Y.G. Lu,"Experimental Research on Prediction Model of Concrete Shrinkage and Creep,"Journal of Central South University: Science and Technology, vol. 47, no. 10, pp. 3515-3522, 2016.

[17] S. Mašović, S. Stošić, N. Pecić,"Research of Long-term Behaviour of Non-prestressed Precast Concrete Beams Made Continuous,” Engineering Structures, vol. 70, pp. 11-22, 2016.

[18] B. Hedegaard, C. French, C. Shield,"Investigation of Thermal Gradient Effects in the I-35W St. Anthony Falls Bridge,”Journal of Bridge Engineering, vol. 18, no. 9, pp. 890-900, 2013.

[19] S. Abid, N. Tayşi, M. Özakça, "Experimental Analysis of Temperature Gradients in Concrete Boxgirders,"Construction and Building Materials, vol. 106, pp. 523-532, 2016.

[20] N.Tayşi, S. Abid, "Temperature Distributions and Variations in Concrete Box-Girder Bridges: Experimental and Finite Element Parametric Studies,"Advances in Structural Engineering, vol. 18, no. 4, pp. 469-486, 2015.

[21] J. Liu, Y.J. Liu, Y.X. Bai, G.L. Liu,"Regional Variation and Zoning of Temperature Gradient Pattern of Concrete Box Girder,’China Journal of Highway and Transport, vol. 33, no. 3, pp. 73-84, 2020. 